\title{
A Inexorabilidade do reúso potável direto
} The Inexorability of direct potable reuse

Data de entrada: 15/05/2013

Data de aprovação: 04/11/2014

Ivanildo Hespanhol

DOI: 10.4322/dae.2014.141

\section{Resumo:}

A política de importar água de bacias cada vez mais distantes para satisfazer o crescimento da demanda começou há mais de dois mil anos com os romanos, dando origem aos seus famosos aquedutos. A prática ainda persiste, resolvendo, precariamente, o problema de abastecimento de água de uma região, em detrimento daquela que a fornece. As soluções mais modernas em termos de gestão de recursos hídricos consistem em tratar e reusar os esgotos já disponíveis nas próprias áreas urbanas para complementar o abastecimento público. A prática de reúso para fins não potáveis já está consagrada em uma grande multiplicidade de países desenvolvidos e em vias de desenvolvimento. Atualmente, a proposta evoluiu para reúso potável por meio da utilização dos sistemas de distribuição existentes, eliminando os custos associados a linhas paralelas para distribuir água de reúso. Os fundamentos ambientais, de saúde pública e gerenciais, assim como os sistemas de tratamento avançados e as técnicas de certificação da qualidade da água atualmente disponíveis, permitem fazer uso de recursos hídricos locais, produzindo "água segura", que não é, certamente, proporcionada por sistemas convencionais, tratando água extremamente poluída. A prática de reúso potável direto para abastecimento público já está estabelecida em diversos estados americanos, na África do Sul, Austrália, Bélgica, Namíbia e Singapura, sem que tenham sido detectados problemas de saúde pública associados. A existência de precedentes bem-sucedidos, a visão de segurança adicional no abastecimento de água e a disponibilidade de água com qualidade elevada são fatores positivos para a aceitação comunitária da prática de reúso potável direto. Por outro lado, fatores negativos associados à percepção e aceitação pública podem, se não forem adotadas estratégias de comunicação e de educação comunitária, se caracterizar como elementos inibidores da prática. $O$ maior fator limitante, entretanto, se origina nos órgãos reguladores, que insistem em adotar posturas conservadoras, propondo normas irracionalmente restritivas, que apenas contribuem para impedir a importantíssima prática de reúso de água no Brasil.

Palavras-chave: Gestão de recursos hídricos. Sistemas de tratamento avançado. Reúso de água. Reúso potável direto. 


\section{Abstract:}

Watershed transposition is a two thousand years policy developed by the Romans to satisfy their continuously growing water demand, leading to the construction of an extensive network of aqueducts. The practice remains nowadays, solving the supply problems in one region in detriment of another. The modern solution in terms of water resources managements to treat and to reuse wastewater locally available in the urban settings to complement public supplies. Non potable reuse is widely applied in a wide range of developed as well as in industrializing countries. Presently, the proposal has been evolved to potable reuse by making use of the existing distribution systems, eliminating, in this way, the costs associated to parallel lines to supply reuse water. The basic environmental, public health and managerial criteria, as well as advanced treatment and water quality certification systems now available allow for the use of local water resources to produce "safe water", which is, certainly not provided through conventional systems treating highly polluted waters. Potable direct reuse for public supply has already been established in several states of the United States as well in Australia, Belgium, Namibia, Singapore and South Africa, without detected health effects associated. Existing well succeeded precedents, the expectancy of an additional security on water supply and water quality are important positive factors for the acceptance of direct potable reuse. On the other hand negative factors associated to public perception and acceptance, may, if community information and awareness is not adequately promoted, be a source of restriction for direct potable reuse. However, the most critical negative factors originate from regulatory bodies, by adopting a conservative behavior and proposing irrationally restrictive regulations, contributing only for the hindering of the very important practice of water reuse in Brazil.

Keywords: Water resources management. Advanced treatment systems. Water reuse. Direct potable reuse.

\section{SUSTENTABILIDADE, ROBUSTEZ, RESILIÊNCIA E VULNERABILIDADE}

O termo 'sustentabilidade' é um conceito técnico/filosófico genérico que, se considerado independente de variáveis sistêmicas específicas, não pode ser expresso em termos quantitativos. Em um sistema de abastecimento de água, a sustentabilidade deve ser interpretada como a probabilidade de suprir, permanentemente, demandas crescentes, em condições satisfatórias. As variáveis mais importantes que estabelecem, ou não, uma condição de sustentabilidade são: (i) robustez, refletindo desempenho consistente e capacidade de atender a uma demanda crescente mesmo em condições de diversos tipos de estresse; (ii) resiliência, ou seja, a habilidade do sistema de recuperar seu estado satisfatório após sofrer impactos negativos, como, por exemplo, a perda de capacidade de atendimento de fontes de abastecimento; e, (iii) vulnerabilidade, isto é, a magnitude da falha de um sistema de abastecimento (HASHIMOTO et al., 1982).

Sistemas como o que abastece a Região Metropolitana de São Paulo (RMSP) não são portanto, sustentáveis, porque são pouco robustos e possuem resiliência praticamente nula, uma vez que permanecem na dependência de recursos oriundos de bacias que, por sua vez, também estão submetidas a condições extremas de estresse hídrico.

A cultura de importar água de bacias cada vez mais distantes para satisfazer o crescimento da demanda remonta há mais de dois mil anos. Os romanos, que praticavam uso intensivo de água 
para abastecimento domiciliar e de suas termas, procuravam, de início, captar água de mananciais disponíveis nas proximidades. À medida que estes se tornavam poluídos pelos esgotos dispostos sem nenhum tratamento ou ficavam incapazes de atender à demanda, passavam a aproveitar a segunda fonte mais próxima e assim sucessivamente. Essa prática deu origem à construção dos grandes aquedutos romanos, dos quais existem, ainda, algumas ruínas, em diversas partes do mundo (BOWDOUIN COLLEGE, 2006; SWANSEA UNIVERSITY, 2006).

A sistemática atual é pré-histórica e irracional, resolvendo precariamente o problema de abastecimento de água em uma região, em detrimento daquela que a fornece. Há, portanto, necessidade de adotar um novo paradigma que substitua a versão romana de transportar sistematicamente grandes volumes de água de bacias cada vez mais longínquas e de dispor os esgotos, com pouco ou nenhum tratamento, em corpos de água adjacentes, tornando-os cada vez mais poluídos (HESPANHOL, 2012).

Como confirmação do critério de planejamento de importar recursos hídricos de bacias distantes, está em fase de projeto executivo a captação de água junto ao reservatório Cachoeira do França, no rio São Lourenço, Alto Juquiá, para uma produção média de $4,7 \mathrm{~m}^{3} / \mathrm{s}$ e máxima de $6,0 \mathrm{~m}^{3} / \mathrm{s}$ (SABESP, 2011). O sistema adutor, incluindo as linhas de água bruta e de água tratada, é de aproximadamente 100 quilômetros, atingindo a RMSP, após um recalque superior a 300 metros. O projeto, além de envolver os já ultrapassados sistemas convencionais de tratamento, não apresenta quaisquer aspectos de viabilidade técnica, econômica e ambiental, pois vai demandar um investimento de 2,2 bilhões de reais. Nenhuma consideração adicional foi feita pelos tomadores de decisão quanto ao volume de esgotos que seria gerado em função dessa nova adução, ou seja, de aproximadamente 3,8 $\mathrm{m}^{3} / \mathrm{s}$, assumindo-se um coeficiente de retorno de $80 \%$, que certamente será disposto, sem tratamento, nos já extremamente poluídos corpos hídricos da RMSP.

\section{REÚSO DE ÁGUA E SUSTENTABILIDADE}

Nesse cenário, uma solução sustentável seria a de tratar e reusar, para fins benéficos, os esgotos já disponíveis nas áreas urbanas para complementar o abastecimento público. Essa prática contribuiria substancialmente para o aumento da robustez dos sistemas e tornaria o conceito de resiliência pouco significativo, uma vez que eliminaria as condições de estresse associadas à redução da disponibilidade hídrica em mananciais utilizados para abastecimento público.

Numa primeira etapa, essa proposta se desenvolveu em termos de reúso para usos urbanos não potáveis. Nos últimos anos, vem se ampliando no sentido de adotar o reúso para fins potáveis. Esse conceito, além de constituir solução econômica e ambientalmente correta, proporcionará água segura, o que não é, atualmente, fornecido por sistemas convencionais de tratamento, que tratam águas provenientes de mananciais extremamente poluídos, inclusive com poluentes emergentes.

As tecnologias modernas de tratamento e de certificação da qualidade da água disponíveis atualmente têm grande potencial para viabilizar a utilização de mananciais desprotegidos, permitindo, por extensão, o reúso direto de água para fins potáveis. A prática do reúso potável direto, pelo fato de empregar tecnologia e sistemas de controle e de certificação modernos, proporcionará, certamente, melhores benefícios em termos de saúde pública do que o emprego das tecnologias de tratamento convencionais para tratar água oriunda de mananciais extremamente poluídos contendo altas concentrações de esgotos domésticos e industriais. 


\section{SISTEMAS DE REÚSO POTÁVEL}

Sistemas de reúso potável podem ser concebidos como Reúso Potável Indireto Planejado (RPIP) ou Não Planejado (RPINP) e reúso potável direto.

\subsection{RPINP}

Sistemas de de RPINP, na grande maioria das vezes inconscientes, são praticados extensivamente no Brasil. Exemplos típicos são os lançamentos de esgotos (tratados ou não) e a coleta a jusante para tratamento e abastecimento público, praticados em cadeia, por diversos municípios, ao longo do rio Tietê e do rio Paraíba do Sul. $\mathrm{Na}$ RMSP, a reversão do corpo central e do braço do Taquacetuba do reservatório Billings para o reservatório Guarapiranga também constitui um sistema de reúso de água para fins potáveis, o qual não foi concebido dentro dos critérios e tecnologias associados às práticas de reúso, pois as águas coletadas do reservatório Guarapiranga, após a reversão do reservatório Billings, são tratadas na Estação de Tratamento de Água (ETA) do Alto da Boa Vista por meio de um sistema convencional de tratamento.
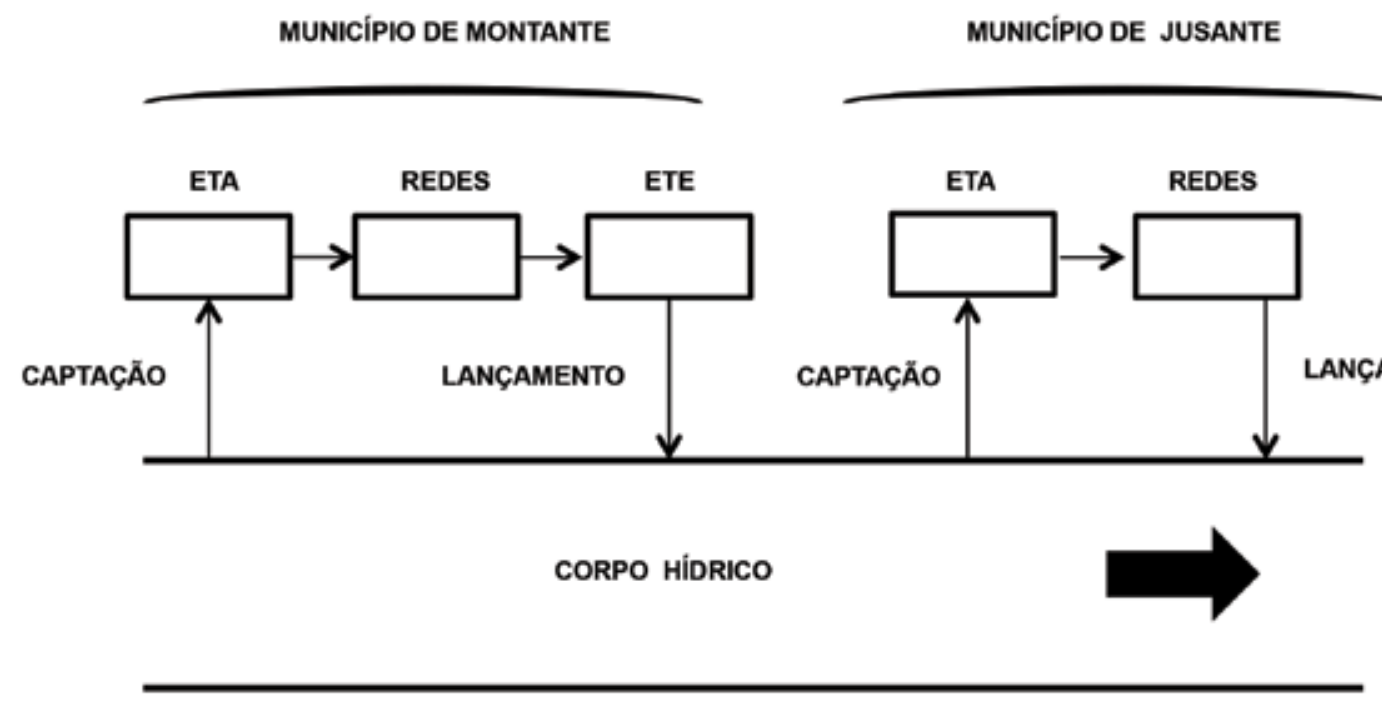

Figura 1: Cenário típico de sistemas de reúso indireto não planejado efetuados em série.
Causa estranheza que o órgão regulador local, extremamente vinculado a normas irracionais e extremamente restritivas, ignore completamente os problemas ambientais e de saúde pública causados por essa sequência de lançamentos de esgotos brutos e de captação imediatamente a jusante para abastecimento público de água.

Um esquema ilustrativo de sistema de RPINP é mostrado na Figura 1.

\subsection{RPIP}

Conceitualmente, o RPIP deve ser constituído por um sistema secundário de tratamento de esgotos, geralmente de lodos ativados e, mais modernamente, de sistemas de biomembranas submersas (iMBRs), seguido de sistemas de tratamento avançado e, se necessário, de um balanceamento químico antes do lançamento em um corpo receptor, superficial ou subterrâneo, aqui designado como Atenuador Ambiental (AA), como mostrado esquematicamente na Figura 2.

Os AAs podem ser corpos hídricos naturais associados aos sistemas de reúso potável direto pla- 


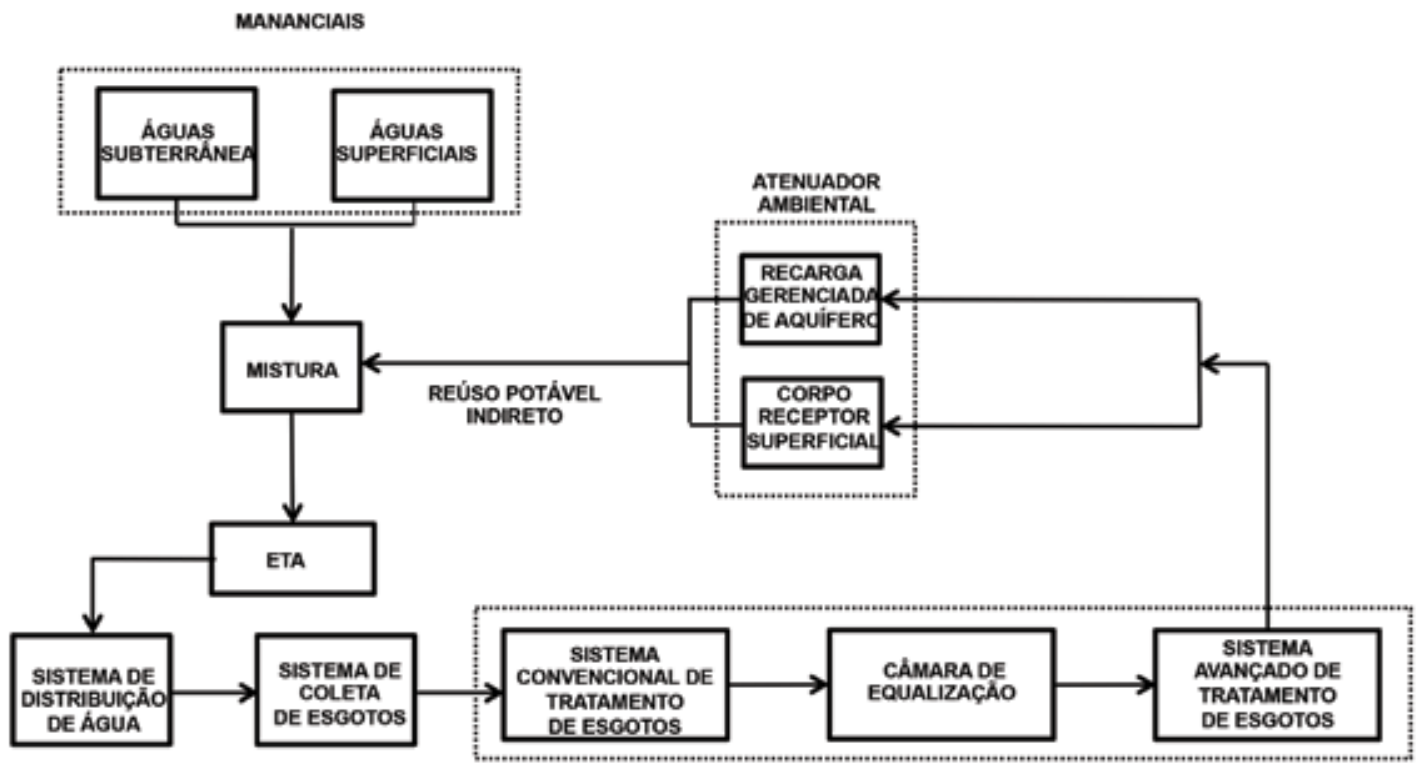

Figura 2 - RPIP.

Fonte: Adaptado de Tchobanoglous et al. (2011).

nejado, como aquíferos confinados, nos quais a recarga gerenciada é efetuada com os esgotos tratados, ou corpos receptores naturais, rios, lagos ou reservatórios construídos para regularização de vazões, tomada de água, geração de energia elétrica ou usos múltiplos, nos quais os esgotos tratados são lançados e posteriormente captados para reúso indireto. Os AAs, tanto subterrâneos quanto superficiais, têm o objetivo de, por efeitos de diluição, sedimentação, adsorção, oxidação, troca iônica etc., atenuar as baixas concentrações de poluentes remanescentes dos sistemas avançados de tratamento utilizados. A legislação do estado da Califórnia (CDPH, 2008) para recarga gerenciada de aquíferos (que poderia ser avaliada e adaptada para condições brasileiras), por exemplo, estabelece uma retenção de seis meses, baseada na hipótese de que cada mês de retenção proporciona a redução de uma ordem de magnitude (99\%) de vírus, obtendo no período total uma redução correspondente a seis ordens de magnitude $(99,9999 \%)$.

Os objetivos básicos dos AAs são:
- proporcionar diluição e estabilização dos contaminantes ainda existentes no efluente tratado;

- proporcionar uma barreira adicional de tratamento para organismos patogênicos e/ou elementos-traços, por meio de sistemas naturais;

- proporcionar tempo de resposta em caso de mau funcionamento do sistema avançado de tratamento;

- proporcionar percepção pública de que ocorre um aumento da qualidade da água;

- proporcionar ao público consumidor a percepção de que ocorre uma dissociação entre esgoto e água potável.

O reúso potável direto planejado é difícil de ser aplicado nas condições atuais brasileiras, devido às seguintes características técnicas, ambientais, legais e institucionais:

- os corpos receptores superficiais que poderiam operar como AAs são geralmente poluídos, não possibilitando os efeitos purificadores secundários desejados. $\mathrm{Na}$ realidade, o oposto 
ocorreria, pois efluentes altamente purificados por processos avançados de tratamento seriam contaminados, em face dos elevados níveis de poluição de grande parte dos corpos hídricos;

- por desconhecimento da importância e benefícios inerentes, a prática de recarga gerenciada de aquíferos é formalmente rejeitada pelos legisladores e por alguns órgãos defomento, quevêm continuamenterecusando o desenvolvimento de estudos e projetos que dariam subsídios para o desenvolvimento de uma norma e de códigos de prática nacionais sobre o tema (HESPANHOL, 2009). Por essa razão, não há no Brasil possibilidade atual de utilizar aquíferos subterrâneos como AAs;

- efluentes lançados em corpos receptores, superficiais ou subterrâneos, não passam automaticamente a ser do domínio das entidades ou companhias de saneamento que procederam ao tratamento e respectiva descarga. Uma vez lançados ao meio ambiente, a captação correspondente, total ou parcial, fica submetida aos critérios de outorga e à respectiva cobrança pelo uso da água. De maneira geral, as companhias de saneamento não farão grandes investimentos em sistemas de tratamento para obter uma água de qualidade elevada sobre a qual não teriam domínio automático. Apenas quando ocorrerem condições logísticas especiais, ou seja, quando a captação outorgada for efetuada muito próxima aos pontos de lançamento ou quando o reservatório que recebe os efluentes tratados for operado pela própria companhia de saneamento que efetua o reúso, poderá o investidor auferir os benefícios do elevado grau de tratamento conferido a seus efluentes, para implementar sistemas de RPIP.

Verifica-se, portanto, que a implantação de sistemas de RPIP não tem, atualmente, condições técnicas e econômicas para ocorrer no Brasil. No fu- turo, seria possível que essa modalidade de reúso pudesse vir a ser implantada, caso fosse promulgada legislação nacional sobre recarga gerenciada de aquíferos e/ou a obrigatoriedade de que os esgotos só podem ser lançados em corpos superficiais após níveis de tratamento superiores aos secundários, hoje adotados apenas em pequena parte do país.

Há uma enorme gama de sistemas de RPIP, tanto experimentais quanto públicos, operando em diversos países. Um sistema administrado pela Companhia Intermunicipal de Água VeurneAmbacht (IWVA), em Koksijde, no extremo norte da Bélgica, está em operação desde julho de 2002. A Estação de Tratamento de Efluentes (ETE) de Wulpen, constituída por um sistema de lodos ativados, foi construída em 1987 e reformada em 1994 para proporcionar remoção de nutrientes. Seu efluente é encaminhado à estação de tratamento avançado de Torreele, na qual passa por unidades de ultrafiltração (ZeeWeed, ZW 500C da Zenon) e, em seguida, por unidades de osmose reversa (30LE-440 da Dow Chemical). O efluente da ETA de Torreele é, após um transporte de aproximadamente 2,5 quilômetros, infiltrado no aquífero arenoso, não confinado, de Saint André, com o objetivo de remover organismos patogênicos e traços de produtos químicos que possam ter ultrapassado a barreira de osmose reversa. A água é recuperada do aquífero a distâncias variando entre 33 e 153 metros do ponto de recarga, por meio de 112 poços, a profundidades variando entre $8 \mathrm{e}$ 12 metros. 0 extensivo sistema de monitoramento efetuado mostrou a excelente qualidade da água potável produzida. As análises efetuadas em 2007 nos efluentes do sistema de osmose reversa indicaram a ausência de produtos farmacêuticos quimicamente ativos e de disruptores endócrinos acima dos limites de detecção de 0,5 a $10 \mathrm{ng} / \mathrm{L}$ (VAN HOUTTE; VERBAUWHEDE, 2008; VANDENBOHEDE et al., 2008). 
Um dos maiores e mais conhecidos sistemas de RPIP é o de Orange County, situado em Fountain Valley, na Califórnia. Seu efluente é encaminhado, sem desinfecção, à estação de tratamento avançado de Water Factory 21, pertencente ao Orange County Water District, cuja produção é de aproximadamente 82 milhões de metros cúbicos por ano. $\mathrm{O}$ sistema antigo de tratamento, composto por sistema de coagulação/floculação com cal, extração de amônia, recarbonatação, filtração, adsorção em carvão ativado, desinfecção e osmose reversa (TCHOBANOGLOUS; BURTON, 1991), foi substituído, a partir de 2008 e após extensivos estudos pilotos, pelo sistema apresentado na Figura 3. Parte da água produzida é dirigida às bacias de infiltração de Kraemmer e Miller e parte, aos poços de injeção, utilizados para evitar a pe- netração da cunha salina no aquífero costeiro, ao longo da Ellis Avenue.

\subsection{Reúso potável direto}

Reúso potável direto consiste no tratamento avançado de efluentes domésticos e sua introdução em uma ETA cujo efluente adentra, diretamente, um sistema público de distribuição de água, sem que ocorra a passagempor AAs, tanto superficiais quanto subterrâneos. $O$ esgoto, após tratamento avançado, poderá ser introduzido diretamente em uma ETA ou em um reservatório de mistura a montante dela, quando vazões complementares, tanto de origem superficial quanto subterrânea, compõem a vazão total a ser tratada no sistema de reúso.

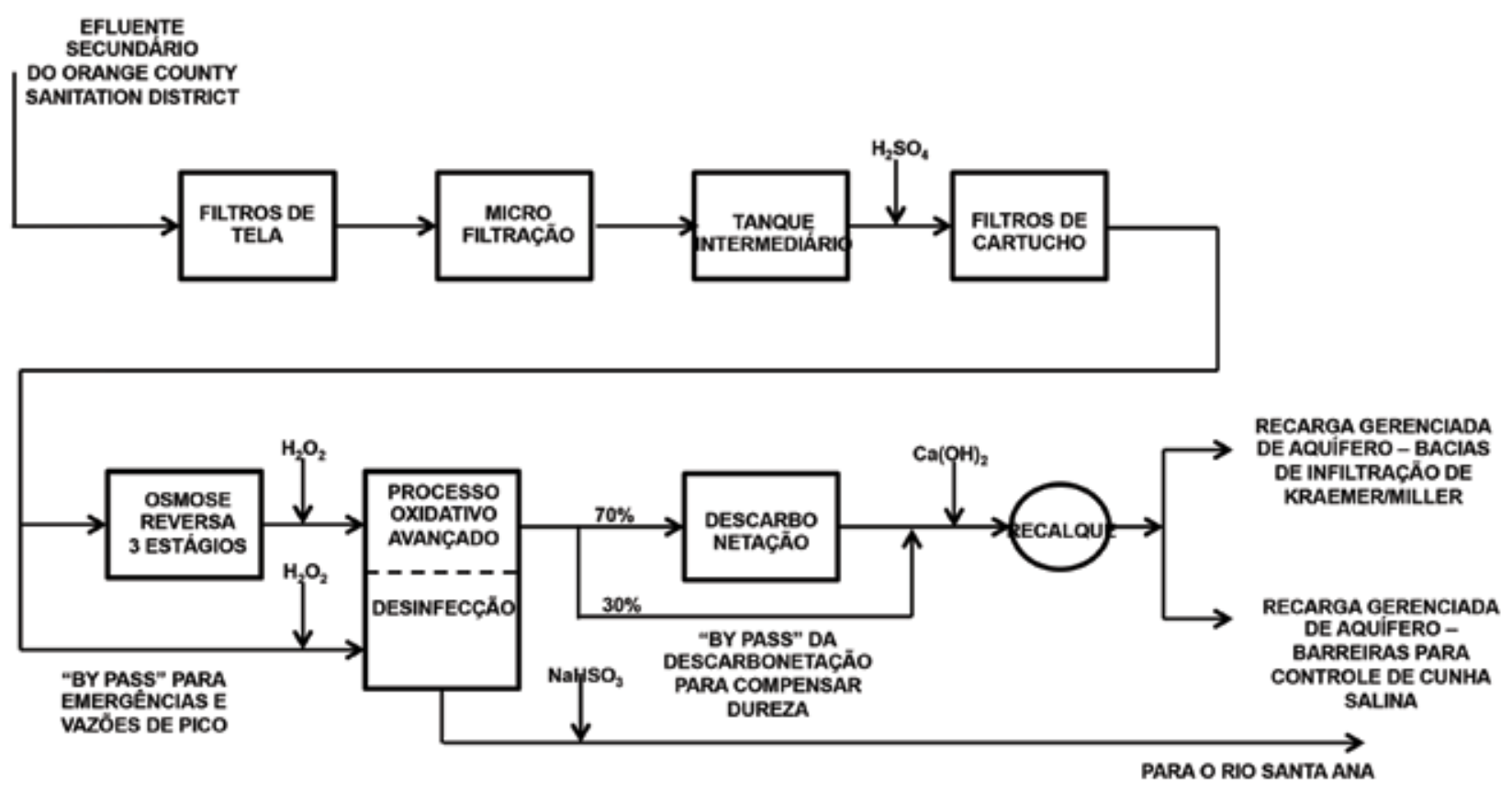

Figura 3 - Orange County Water District, Fountain Valley, CA. Fonte: Adaptado de Tchobanoglous et al., (2011). 


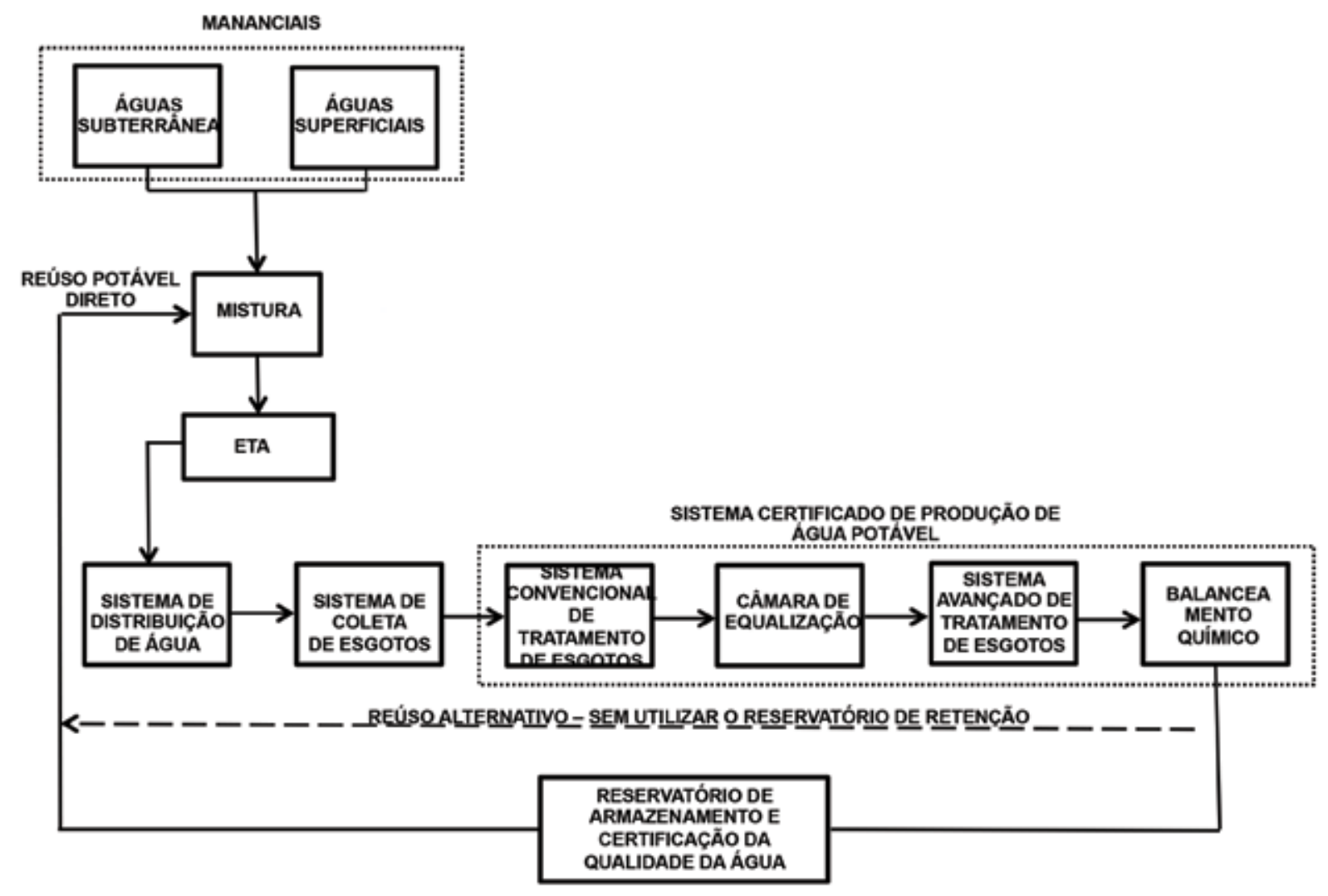

Figura 4 - Reúso potável direto.

Fonte: Adaptado de Tchobanoglous et al., (2011).

Conforme mostrado na Figura 4 após tratamento secundário (sistemas convencionais ou sistemas Membrane Bio Reactor - MBR), os esgotos passariam por câmara de equalização, por um sistema de tratamento avançado e por uma eventual câmara para balanceamento químico, seguida de reservatório de retenção, antes de serem encaminhados à ETA, após mistura a ser efetuada com águas superficiais e/ou subterrâneas.

A necessidade de balanço químico deverá ser verificada quando não ocorrer a complementação com fontes superficiais ou subterrâneas ou quando a porcentagem de água de reúso for bastante elevada. Nesse caso, pode ser conveniente efetuar a remineralização da água para evitar problemas de saúde pública, melhorar o gosto e prevenir corrosão a jusante.

O reservatório de retenção pode ser natural (um pequeno lago ou reservatório isolado) ou construído. Deve ser adequadamente projetado para servir como um sistema intermediário entre o sistema de tratamento de esgotos e o sistema de tratamento de água potável. Se o sistema envolver um grau significativo de variabilidade no sistema de tratamento de esgotos, esse reservatório deverá ser de grandes dimensões, permitindo tempo suficiente para responder às eventuais deficiências do processo e efetuar uma certificação extensiva do efluente produzido. Caso apresente um elevado grau de confiabilidade, o reservatório de retenção poderá ter dimensões 
reduzidas ou mesmo não ser incluído no sistema de reúso.

Os objetivos básicos dos reservatórios de retenção e certificação são:

- compensar a variabilidade entre a produção e a demanda de água;

- compensar a variabilidade da qualidade da água produzida (praticamente desnecessário com sistemas avançados de tratamento);

- prover um mínimo de tempo para detectar e atuar sobre as eventuais deficiências de processo antes da introdução da água tratada no sistema de distribuição.

Além disso, devem ser projetados e construídos com elevado nível de segurança estrutural e ambiental, prevenir poluição externa, evitar perdas por evaporação, dispor de sistemas hidráulicos capazes de efetuar descargas rápidas quando necessário e dispor de instalações para amostragem e monitoramento.

A Figura 5 mostra, esquematicamente, um sistema de certificação que inclui três reservatórios dispostos em série, cada um com volume de água potável equivalente a 12 horas de produção do sistema avançado de tratamento (ATSE, 2013).

\section{TECNOLOGIA DISPONIVEL PARA REÚSO POTÁVEL DIRETO}

A questão adjacente que ainda perdura em muitos setores conservativos é se há, atualmente, disponibilidade de tecnologia adequada (operações, processos unitários e sistemas integrados) e técnicas de certificação da qualidade da água que permitam produzir, consistentemente, água segura a partir de esgotos domésticos, respeitando critérios econômicos e de proteção

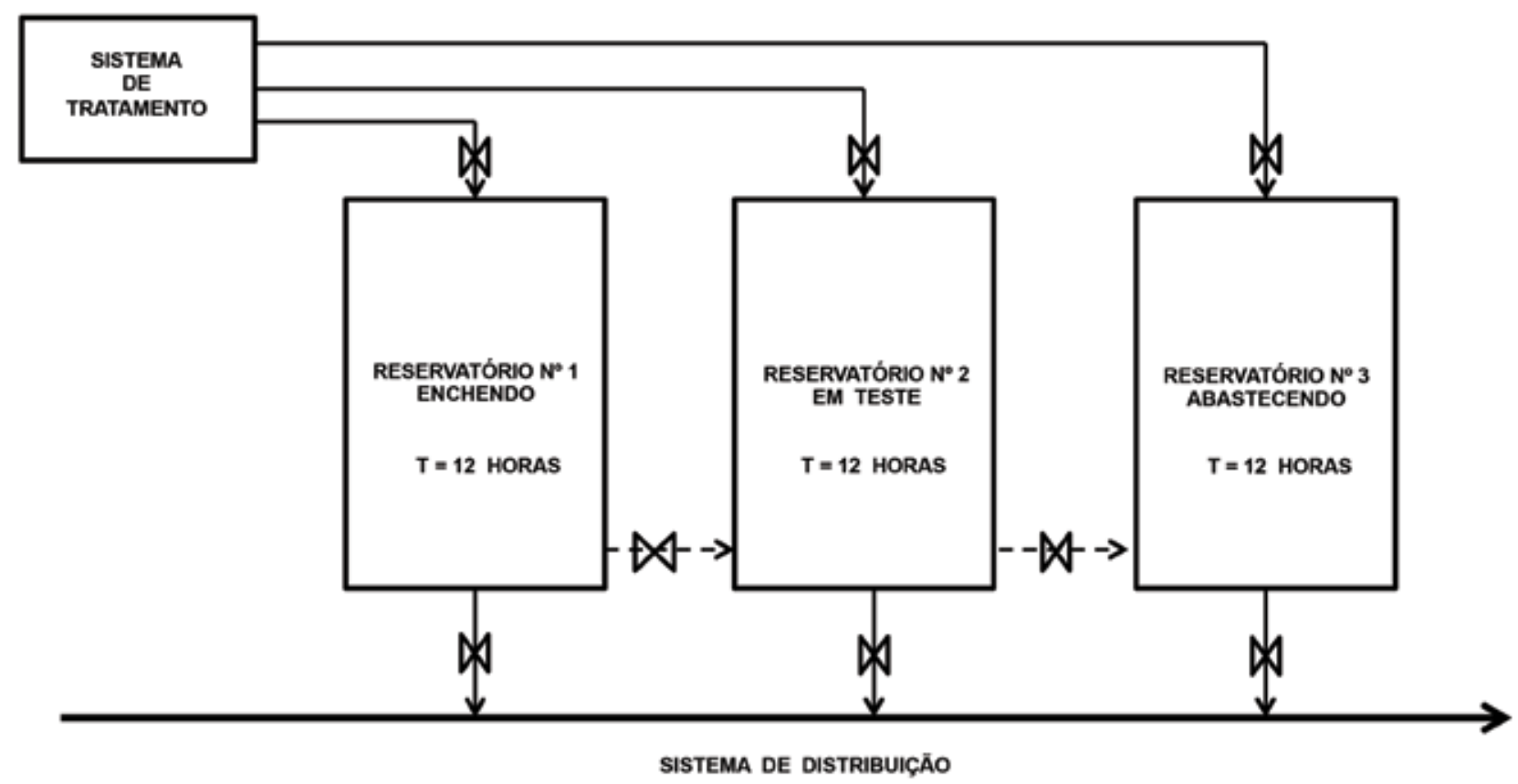

Figura 5 - Reservatório de retenção e de certificação. Fonte: Adaptado de ATSE (2013). 
da saúde pública dos consumidores. Em seguida são apresentados, de maneira resumida, três processos unitários básicos que, em conjunção com processos tradicionais, como coagulação/floculação, filtração, desinfecção etc., podem compor sistemas avançados de tratamento, que devem ser avaliados com o objetivo de produzir consistentemente água de reúso para fins potáveis, em sistemas diretos.

\subsection{Operações e processos unitários potenciais}

Os processos ou sistemas unitários que poderão ser utilizados para compor sistemas avançados de tratamento para reúso são basicamente os seguintes:

a. sistemas de membranas: os poluentes químicos tradicionais e emergentes, mesmo os de baixa massa molecular, como os disruptores endócrinos, assim como organismos patogênicos de dimensões muitos pequenas, como os oocistos de Cryptosporidium spp., podem ser efetivamente removidos por sistemas de membrana de ultrafiltração, nanofiltração e osmose reversa. A Organização Mundial da Saúde (OMS) avalia que, dependendo dos tipos de membrana utilizados e de suas características operacionais, a remoção máxima de vírus, bactérias e protozoários pode ser superior a ordens de magnitude 6,5, 7 e 7, respectivamente (WHO, 2011);

b. carvão biologicamente ativado: unidades de carvão biologicamente ativado são sistemas utilizados em tratamento avançado de água, principalmente para remover material orgânico (geralmente biodegradáveis), material não orgânico (compostos estáveis e de difícil degradação) e organismos patogênicos, contidos em águas superficiais ou subterrâneas. A remoção de contaminantes é processada por meio de três mecanismos básicos: biodegradação, adsorção de micropoluentes e filtração de sólidos suspensos (ASANO et al., 2007). O biofilme formado nos poros e superfície do carvão ativado (em pó ou granular) consome a matéria orgânica, produzindo, como subprodutos, água, dióxido de carbono, biomassa e moléculas orgânicas simples. A promoção da atividade biológica é efetuada pela ação de um oxidante forte, geralmente ozônio, que é aplicado na entrada da unidade filtrante;

c. processos oxidativos avançados (POAs): envolvem a geração do radical livre hidroxila $\left(\mathrm{OH}^{\circ}\right)$, um oxidante forte com capacidade de oxidar compostos que não são passíveis de ser oxidados por oxidantes convencionais, como oxigênio, ozônio e cloro. (TCHOBANOGLOUS et al., 2003). A importância de POAs em sistemas de reúso potável direto é vinculada ao fato de que mesmo efluentes de sistemas de tratamento terciário (inclusive permeados de sistemas de osmose reversa) podem conter traços de compostos orgânicos naturais ou sintéticos (ASANO et al., 2007).

\subsection{Sistemas avançados de tratamento para reúso potável direto}

O sistema avançado de tratamento deverá ser concebido em função das características do esgoto a ser tratado e da qualidade de eventuais fontes adicionais de água que serão tratadas na ETA. Dependendo da qualidade dessas fontes extras, (presença de produtos químicos e de organismos patogênicos, como oocistos de Cryptosporidium spp.), a ETA deverá, também, conter sistemas avançados de tratamento, como ultrafiltração e POAs.

O sistema de tratamento avançado a ser construído (após tratamento convencional por sistemas de lodos ativados ou equivalentes) deverá integrar os conceitos de barreiras múltiplas, sendo imprescindível executar estudos pilotos para identificar a consistência na produção de efluentes adequados, fornecer parâmetros de projeto realistas, identificar problemas de operação e manutenção e avaliar os custos associados. 


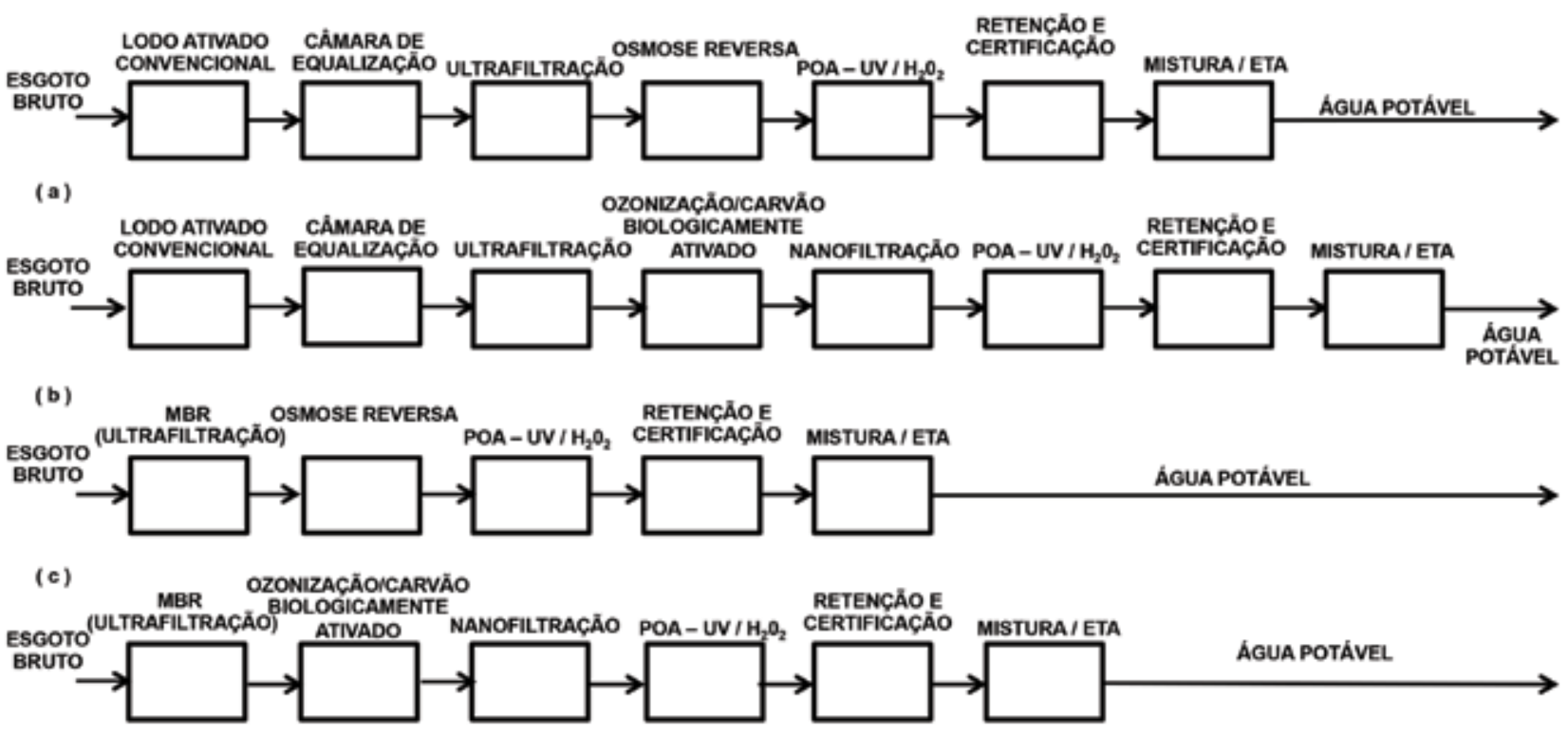

(d)

Figura 6 - Sistemas avançados de tratamento para reúso potável.

Fonte: Adaptado de Leverenz et al. (2011) e Tchobanoglous et al. (2011).

Considerando a elevada capacidade de remoção de poluentes críticos dos processos unitários descritos, os sistemas de tratamento para reúso potável direto a ser considerados para avaliação, em função de efluentes específicos e de características locais, são os quatro sistemas esquematizados na Figura 6.

Os sistemas (a) e (b), que utilizam efluentes de sistemas de tratamento de esgotos por lodos ativados, necessitam de câmaras de equalização devido à variação de qualidade dos efluentes produzidos, principalmente quando são empregados sistemas de aeração prolongada. O sistema (a) é composto por unidades de osmose reversa (com pré-tratamento por ultrafiltração) e de POA, por meio de $\mathrm{UV} / \mathrm{H}_{2} \mathrm{O}_{2}$. Como nos demais sistemas mostrados na Figura 6, o efluente tratado passa pelo reservatório de retenção/armazenamento/ certificação, pela câmara de mistura e, finalmente, pela ETA, produzindo água potável. O sistema (b) emprega unidades de ultrafiltração, carvão biologicamente ativado com ozônio, nanofiltração e POA, por meio de de $\mathrm{UV} / \mathrm{H}_{2} \mathrm{O}_{2}$. Os sistemas (c) e (d) integram os mesmos processos unitários de tratamento, mas efetuam o tratamento biológico mediante sistemas MBR com membranas de ultrafiltração. Assim, não necessitam, devido à consistência de qualidade proporcionada pelas unidades de ultrafiltração, de câmaras de equalização. O sistema (c) integra, após o sistema MBR, unidades de osmose reversa e de POA, por meio de UV/ $\mathrm{H}_{2} \mathrm{O}_{2}$; já o sistema (d) é composto por carvão biologicamente ativado com ozona, nanofiltração e POA, por meio de UV/ $\mathrm{H}_{2} \mathrm{O}_{2}$. 


\section{A EXPERIÊNCIA MUNDIAL EM REÚSO POTÁVEL DIRETO}

Assim como os sistemas de RPIP, há uma significativa quantidade de sistemas de reúso potável direto, tanto experimentais em operação, implantados quanto em diversos estados americanos, na África do Sul, Austrália, Bélgica, Namíbia e Singapura, sem que tenham sido detectados problemas de saúde pública associados. Alguns desses exemplos são mostrados a seguir.

\section{Windhoek, Namíbia}

O município de Windhoek, com aproximadamente 250.000 habitantes (censo de 2001), está situado na Namíbia, sudoeste da África, ao sul do deserto do Saara. O reúso potável direto vem sendo praticado há mais de 40 anos, sem que problemas de saúde pública associados à água potável tenham sido identificados (VAN DER MERWE et al., 2008).
Além de um completo sistema de monitoramento da qualidade da água, é utilizado o princípio de pontos críticos de controle (ABNT, 2002; DAMIKOUKA et al., 2007), o que traz uma maior segurança de saúde pública aos usuários.

O esquema do sistema avançado atual, da ETA de Goreangab, após a última ampliação efetuada em 1997, é mostrada na Figura 7.

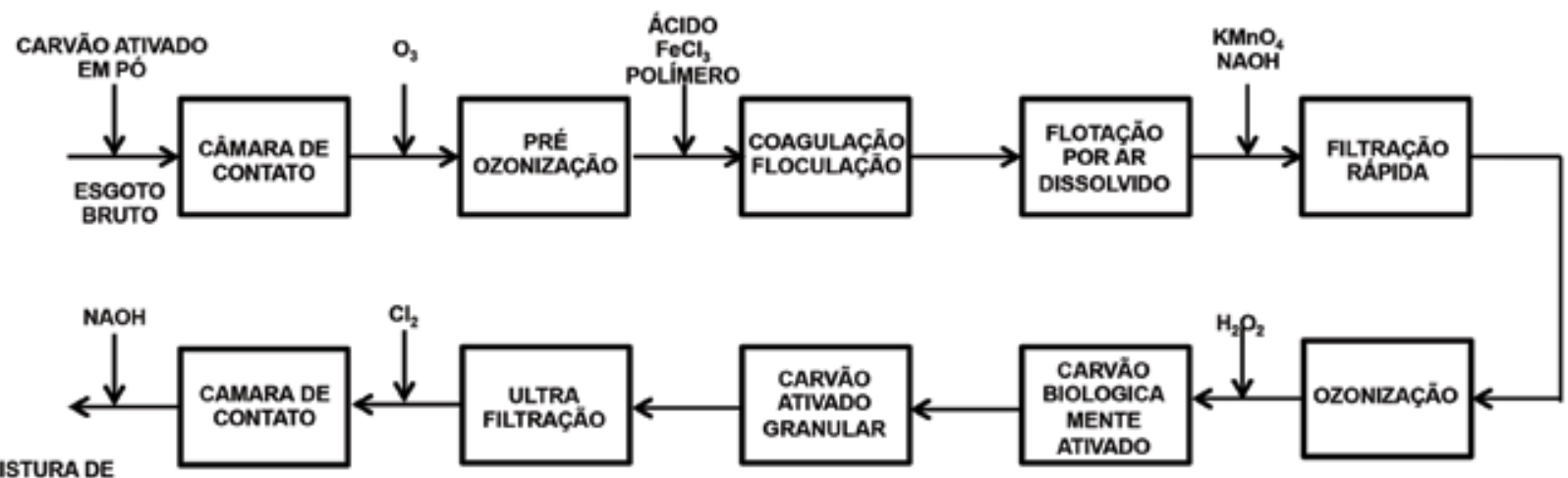

MISTUR

EFLUENTE É
DISTRIBUIČ̃̆O

Figura 7 - Estação de tratamento de Goreangab, em Windhoek, Namíbia, para reúso potável direto, remodelada em 1997. Fonte: Adaptado deVan DerMerwe et al. (2008).

\section{Denver, Colorado, Estados Unidos}

O projeto de demonstração de reúso potável direto da cidade de Denver operou no período de 1985 a 1992 e teve como principal objetivo avaliar os problemas potenciais de saúde pública que poderiam ocorrer. O sistema, alimentado com esgotos secundários sem desinfecção, foi projetado dentro do conceito de barreiras múltiplas montadas em linhas paralelas para permitir manutenção adequada e dar continuidade à operação quando da ocorrência de eventuais falhas em processos e operações unitárias (Figura 8). Foi efetuado um extensivo monitoramento da qualidade da água produzida, utilizando amostras compostas em pe- 
ríodos de 24 horas e avaliando todas as variáveis de qualidade regulamentadas na época. Embora no período dos testes ainda não se tivesse conhecimento de poluentes emergentes que hoje são encontrados em mananciais de todo o mundo, a pesquisa evidenciou que a água produzida apre- sentava qualidade semelhante à água potável distribuída em Denver e atendia a todos os padrões de qualidade de água da Agência de Proteção Ambiental dos Estados Unidos (EPA), da Comunidade Europeia e das diretrizes da OMS (Asano et al, 2007).

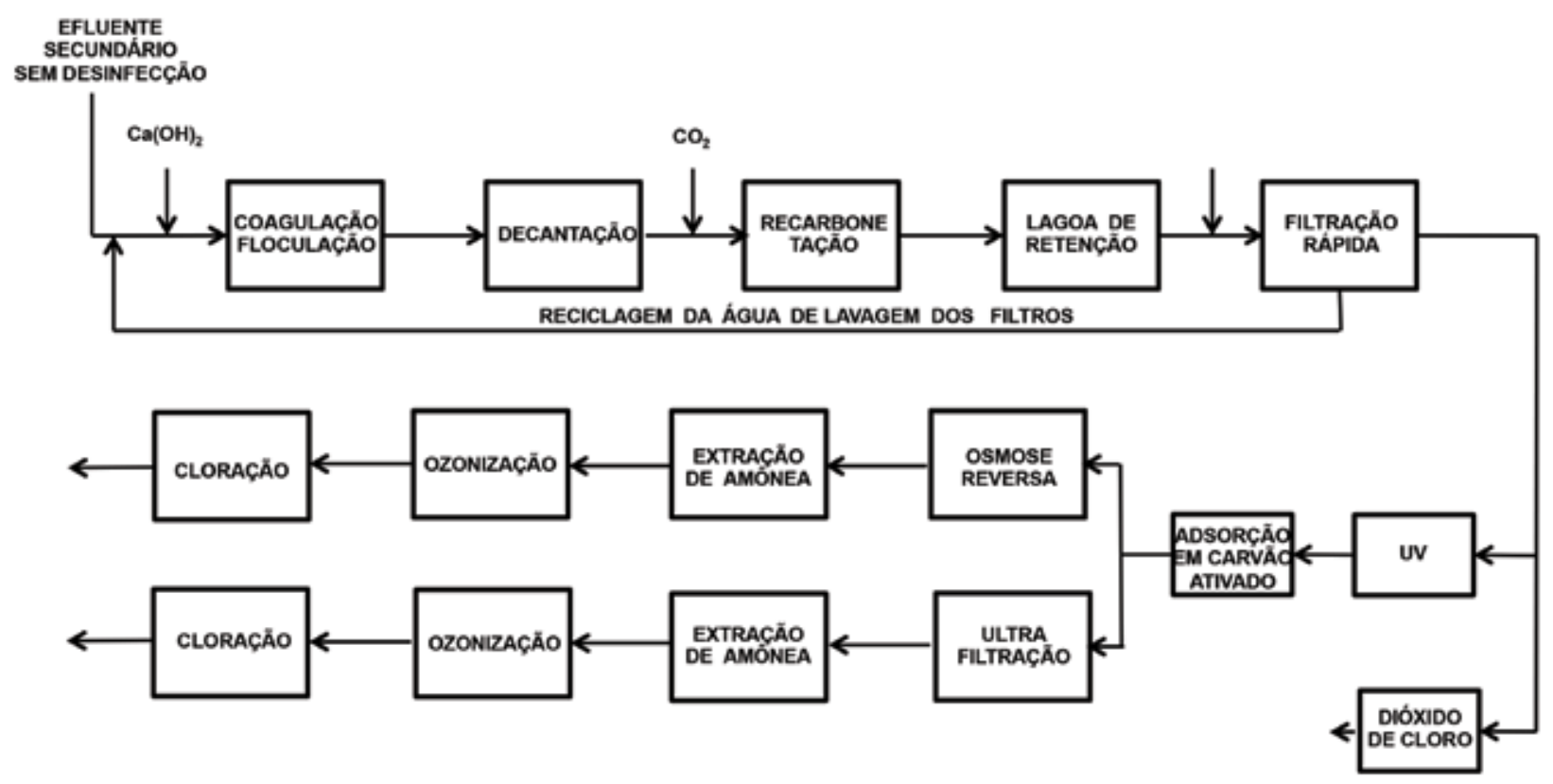

Figura 8 - Estação experimental de tratamento de Denver, Colorado - reúso potável direto Fonte: Adaptado de Asano et al. (2007).

\section{Cloudcroft, Novo Mexico, Estados Unidos}

A pequena vila de Cloudroft se localiza no estado do Novo México, ao sul do município de Albuquerque. Tem uma população de aproximadamente 850 habitantes, que cresce para mais de 2.000 durante fins de semana e feriados. Nessas ocasiões, a demanda de água passa de aproximadamente $680 \mathrm{~m}^{3} /$ dia para um pico próximo a $1.360 \mathrm{~m}^{3} /$ dia. Visando a eliminar o transporte de água por meio de caminhões-pipa durante os picos de consumo, a comunidade decidiu aumentar a disponibilidade de água mediante um sistema de reúso potável direto, utilizando os esgotos domésticos produzi- dos localmente. $\mathrm{O}$ sistema de tratamento adotado, mostrado na Figura 9, inclui em uma primeira fase um reator MBR para tratamento secundário dos esgotos, desinfecção, osmose reversa e um sistema de POA. Seu efluente recebe aproximadamente $51 \%$ (do total produzido) de água bruta oriunda de águas superficiais e de fontes subterrâneas locais. A mistura é mantida em um reservatório durante aproximadamente duas semanas, passando, em seguida, por uma segunda bateria de unidades de tratamento, incluindo ultrafiltração, desinfecção por radiação ultravioleta, carvão ativado e desinfecção final com cloro. 


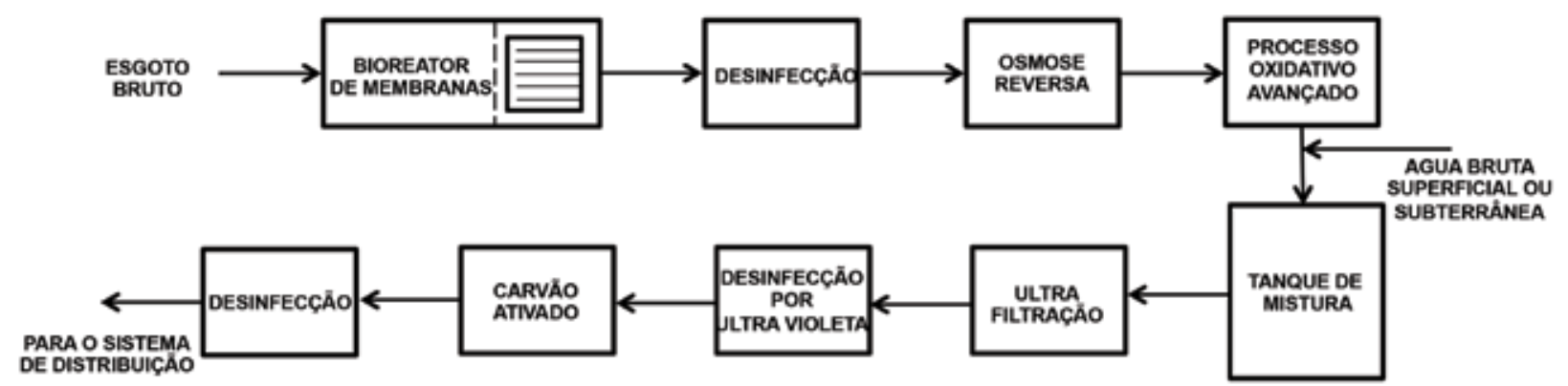

Figura 9 - Sistema de Cloudcroft, Novo México. Fonte: Adaptado Tchobanoglous, et al., (2011).

\section{Big Springs, Texas, Estados Unidos}

Embora o reúso de água seja praticado na região há muito tempo, o Colorado River Water District, que abastece várias comunidades da região, inclusive Big Springs, tomou recentemente a decisão de "reciclar $100 \%$ da água, durante $100 \%$ do tempo". O primeiro projeto de reúso associado a essa diretriz foi o de Big Springs, que está ainda em fase de implementação. Conforme mostrado na Figura 10, o efluente do sistema convencional de lodos ativados existente recebe cloro e passa por um filtro de areia e por descloração. Passa, em seguida, por um sistema de tratamento avançado, constituído por microfiltração, osmose reversa e por um sistema de POA. O efluente purificado por meio desse sistema é encaminhado a um reservatório de mistura com água bruta proveniente do reservatório Spencer e do reservatório Thomas. A água é, finalmente, captada no reservatório de mistura, passando, em seguida, por um sistema de tratamento físico-químico constituído por coagulação/floculação/sedimentação, filtração e desinfecção com cloro. $\mathrm{O}$ efluente desse sistema adentra, diretamente, no sistema de distribuição de água de Big Springs.

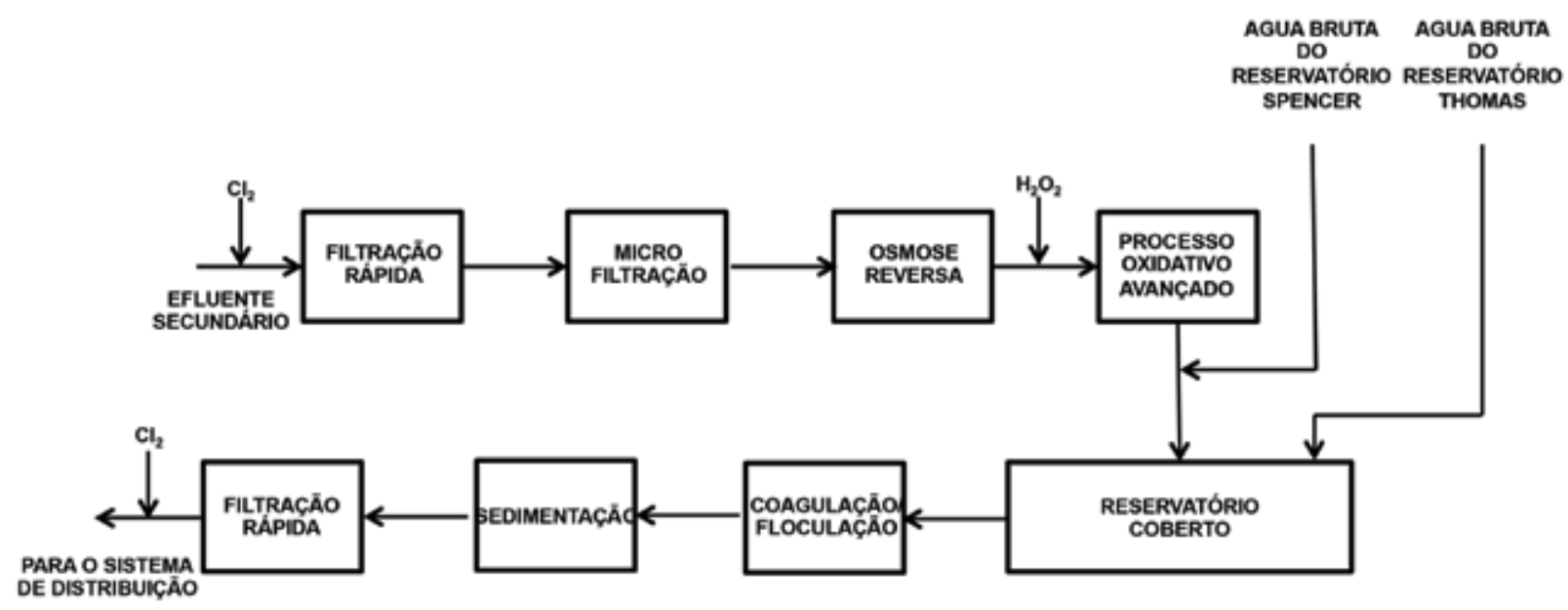

Figura 10 - Big Springs, Texas.

Fonte: Adaptado Tchobanoglous, et al., (2011). 


\section{Beaufort West, África do Sul}

A estação de tratamento avançado de Beaufort West recebe efluentes tratados por sistemas terciários convencionais das ETEs Northern e Kwa Mashu, tendo sido dimensionada para uma vazão de $2.100 \mathrm{~m}^{3} / \mathrm{dia}$ (ATSE, 2013). O sistema, compos- to por ultrafiltração, osmose revers, POA (peróxido de hidrogênio e ultravioleta) e desinfecção por cloro, produzirá $1.000 \mathrm{~m}^{3} / \mathrm{dia}$, que serão mesclados com água tratada pela ETA local de 4.000 $\mathrm{m}^{3} /$ dia, produzindo, portanto, uma vazão total de $5.000 \mathrm{~m}^{3} /$ dia (Figura 11).

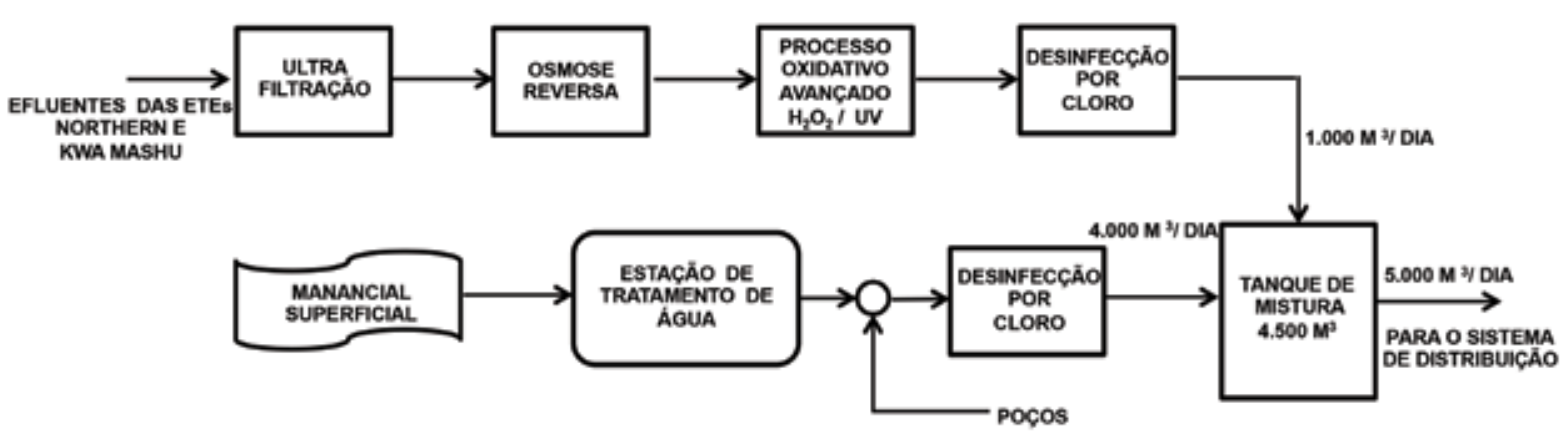

Figura 11 - Sistema de Beaufort West, África do Sul. Fonte: ASTE (2013).

\section{FATORES POSITIVOS PARA IMPLEMENTAÇÃO DO REÚSO POTÁVEL DIRETO}

Em função do cenário crítico descrito, é inevitável que, em um futuro muito próximo, não haja outra solução que não seja a de substituir mecanismos ortodoxos de gestão da água no setor urbano por novos paradigmas, para poder assegurar a sustentabilidade do abastecimento de água, tanto em termos de qualidade quanto de quantidade. A mais importante missão dessa mudança de paradigma está associada à universalização da prática de reúso de água e, mais especificamente, da prática de reúso potável direto, utilizando apenas as redes de distribuição de água atualmente existentes e suas ampliações.

As razões básicas e os fatores positivos que colaboraram para essa mudança significativa nos dogmas vigentes de gestão da água são, basicamente, as seguintes:
- os mananciais para abastecimento de água estão se tornando cada vez mais raros, mais distantes e mais poluídos, tornando-se inviável a sua utilização, como mostrado no primeiro caso relacionado;

- o RPINP, extensivamente praticado no Brasil, é uma prática prejudicial tanto para o meio ambiente quanto para a saúde pública de usuários de sistemas de distribuição de água tratada por meio de sistemas convencionais;

- a implementação de sistemas de RPIP parece ser, atualmente, de pequena viabilidade nas condições brasileiras, uma vez que corpos receptores superficiais, que poderiam operar como AAs, são, como mencionado na seção 3.2, geralmente poluídos, não possibilitando os efeitos purificadores secundários desejados. Da mesma forma, a utilização de aquíferos como AAs também não pode ser realizada na presente conjuntura nacional, uma vez que a 
prática de recarga gerenciada de aquíferos não é, ainda, tecnicamente reconhecida no Brasil;

- com a tecnologia avançada hoje disponível, é possível remover contaminantes-traços orgânicos e inorgânicos e organismos patogênicos que não são removidos em sistemas tradicionais de tratamento de água;

- não haverá necessidade de construir um sistema de distribuição separado para fornecer a água de reúso, podendo ser utilizados os sistemas de distribuição já existentes e suas extensões. No Brasil, não dispomos, infelizmente, de dados unitários de tratamento e de distribuição, mas a avaliação vigente é de que os sistemas de distribuição implicam custo equivalente a $2 / 3$ do total dos custos associados a tratamento e distribuição. Uma avaliação efetuada nos Estados Unidos (TCHOBANOGLOUS et al., 2011) concluiu que o custo total de um sistema paralelo de distribuição de água potável, tratada em nível avançado, oscilaria entre $0,77 \mathrm{R} \$ / \mathrm{m}^{3}$ e $4,08 \mathrm{R} \$ / \mathrm{m}^{3}\left(0,32 \mathrm{US} \$ / \mathrm{m}^{3}\right.$ a 1,70 US $\$\left(\mathrm{~m}^{3}\right)$, enquanto que um sistema típico de tratamento avançado, incluindo sistemas de membranas e POA, oscilaria entre $1,4 \mathrm{R} \$ / \mathrm{m}^{3}$ a $\mathrm{R} \$ 2,33 / \mathrm{m}^{3}$ (US $\$ 0,57 / \mathrm{m}^{3}$ a 0,97 US $\$ / \mathrm{m}^{3}$ ). A eliminação dos custos associados à construção de uma rede paralela para a distribuição de água de reúso compensaria os custos relativamente maiores (em relação a sistemas de tratamento), que seriam atribuídos ao sistema de tratamento avançado. Em alguns casos, como, por exemplo, na RMSP, que depende de importação de águas de bacias distantes, ter-se-ia, ainda, o benefício de evitar a construção de adutoras de água bruta, que implicam a aplicação de recursos elevados para construção, manutenção e recalque;

- água de alta qualidade seria disponibilizada junto aos centros de consumo, sem a necessidade de reversão de bacias. Seria utilizada a água disponível localmente, sem prejudicar o abastecimento de água em bacias em condições de estresse crítico, como, por exemplo, ocorre na RMSP em relação à bacia do rio Piracicaba;

- a tecnologia atual é suficiente para substituir AAs por reservatórios de retenção, em que a água tratada em nível avançado seria adequadamente certificada antes da mistura com outras fontes de água, como mostrado nas Figuras 4 e 5 ;

- a existência de precedentes bem-sucedidos, a visão de segurança adicional no abastecimento de água e a disponibilidade de água com qualidade elevada produzida por sistemas avançados de tratamento são fatores positivos para a aceitação comunitária da prática do reúso potável direto.

\section{FATORES POTENCIALMENTE INIBIDORES DO REÚSO POTÁVEL DIRETO}

Apesar da grande gama de fatores positivos acima relacionados a efetiva implementação de sistemas de reúso potável direto, está fortemente condicionada aos fatores seguintes: (i) restrições legais/institucionais, associadas ao Princípio da Precaução e à legislação vigente sobre crimes ambientais, e; (ii) aspectos psicológicos e culturais associados à percepção e aceitação da prática do reúso de água.

\subsection{Princípio da Precaução}

O princípio da precaução é uma diretriz que busca regular a participação do conhecimento técnico e científico e do senso comum na previsão e no combate a potenciais degradações ambientais, causadas por processos tecnológicos tradicionais ou emergentes. Deve ser aplicado de forma construtiva, elaborando, numa primeira fase, a "análise do risco" por meio da aplicação do conjunto de conhecimentos disponíveis na identificação de potenciais efeitos adversos, assim como dos benefícios ambientais, econômicos, técnicos e so- 
ciais que proporciona (HESPANHOL, 2009; PATTI JÚNIOR, 2007).

A relação entre a ciência e a precaução é uma importante questão conceitual para o gerenciamento prático de riscos tecnológicos. 0 conhecimento adequado do problema para a tomada de decisões requer uma série de atributos, entre os quais, o exame crítico, a transparência, o controle de qualidade, a revisão pelos pares e a ênfase num aprendizado permanente. Apenas após a elaboração exaustiva dessa fase de aprendizado científico e tecnológico é permitido que se passe à fase de "gestão do risco", estabelecendo um marco regulatório que possibilite auferir os benefícios da prática, evitando ou minimizando os riscos correspondentes.

O princípio da precaução não pode, portanto, ser utilizado para impedir o desenvolvimento de tecnologias que podem apresentar certos riscos. Os órgãos reguladores devem assumir o compromisso de lidar com os riscos e as incertezas científicas de forma coerente, permitindo, por outro lado, que os benefícios proporcionados pela prática sejam auferidos em sua plenitude. $O$ cenário mais crítico ocorre, entretanto, quando, com base exclusiva em preconceitos, preferências pessoais e argumentos subjetivos, os tomadores da decisão se recusam a regulamentar processos ou atividades tecnológicas importantes, criando condições para a ocorrência de riscos que poderiam ser evitados pela aplicação de mecanismos adequados de comando e controle.

O que se observa ainda é a usurpação do princípio da precaução no formato de proteção profissional individual, buscando segurança legal por meio da obstrução de processos de regulamentação de práticas importantes e consagradas.

Especificamente no caso do reúso de água, a postura mais detrimentosa para o desenvolvimento da prática é a adoção de regulamentações extremamente restritivas sob a cobertura da pseudopre- caução, buscando apenas a proteção contra penalidades potenciais associadas à Lei n 9.605, de 12 de fevereiro de 1998, que "dispõe sobre as sanções penais e administrativas derivadas de condutas e atividades lesivas ao meio ambiente e dá outras providências” (BRASIL, 1998). Uma normalização racional não meramente copiada de outras fontes, mas adaptada às condições nacionais e cientificamente suportada, eliminaria totalmente a preocupação em relação a penalidades potenciais.

Uma grande reação se esboça atualmente, nos organismos de controle ambiental, nos setores governamentais em seu nível de decisão mais elevado, nos organismos de gestão de recursos hídricos, nos setores empresariais de água e esgoto e nos meios acadêmicos, contra a implementação de normas irracionalmente restritivas, que, por não serem representativas das condições brasileiras, não protegem o meio ambiente e a saúde pública dos grupos de risco, inibindo, por outro lado, a estratégia do reúso, que é, atualmente, o instrumento-chave de gestão da água em áreas com estresse hídrico. Evidentemente, as práticas em consideração são associadas a níveis de riscos de magnitudes diversas, que deverão ser racionalmente avaliados para dar suporte a normas e códigos de práticas realistas.

\subsection{Percepção e aceitação pública da prática de reúso}

O segundo fator, potencialmente limitante, está associado a aspectos culturais e psicológicos de nossa sociedade, face à percepção negativa do consumo de água reciclada e à falta de confiança na segurança de sistemas avançados de tratamento e de certificação da qualidade da água. Além do aspecto social, ocorrem temores associados a riscos políticos, econômicos e ambientais.

Essas posturas sociais negativas podem, entretanto, ser amenizadas por meio de educação ambiental, informação básica sobre a segurança das tecnologias de tratamento e certificação da 
qualidade da água produzida por sistemas de reúso potável direto. A execução de projetos de demonstração e posterior divulgação de resultados de qualidade da água produzida e de estudos epidemiológicos efetuados em associação seriam, também, ferramentas importantes para mostrar a viabilidade ambiental e de saúde pública, proporcionando resultados mais visíveis para amenizar a percepção negativa da prática de reúso potável direto.

\section{CONCLUSÃO E RECOMENDAÇÕES}

O RPINP, extensivamente praticado no Brasil, constitui opção prejudicial tanto para o meio ambiente quanto para a saúde pública de usuários de sistemas de distribuição de água tratada por meio de sistemas convencionais. Por outro lado, a implementação de sistemas de RPIP é, atualmente, pouco viável nas condições brasileiras, uma vez que mananciais subterrâneos e corpos hídricos superficiais, a grande maioria destes com elevados níveis de poluição, não apresentam condições legais e técnicas para ser utilizados como AAs.

A mais importante das mudanças de paradigma que se fazem necessárias consiste em garantir o abastecimento de água em áreas submetidas a estresse hídrico, por meio da promoção da prática de reúso potável direto, sem haver necessidade de instalar uma rede secundária para distribuição de água de reúso.

As razões e as condições básicas que levarão a essa nova dimensão do setor saneamento são as seguintes: (i) os mananciais para abastecimento de água estão se tornando cada vez mais raros, mais distantes e mais poluídos; (ii) a tecnologia avançada hoje disponível permite remover contaminantes, traços orgânicos e inorgânicos e organismos patogênicos, possibilitando a produção de uma água de reúso segura; (iii) os custos de sistemas avançados de reúso são equivalentes ou inferiores aos custos de implantação de uma rede secundária para distribuição de água potável, sendo, portanto, mais econômico efetuar a distribuição da água de reúso potável mediante os sistemas de distribuição atualmente existentes e suas ampliações. Essa proposta se torna economicamente mais favorável quando o abastecimento é dependente da construção de grandes adutoras com desnível elevado, pois permite a utilização de água disponível localmente.

As companhias de saneamento deverão desenvolver estudos e pesquisas, em conjunto com centros de pesquisas certificados, para: (i) avaliar técnica e economicamente operações e processos unitários, assim como sistemas de tratamento avançados para reúso potável direto, dentro das condições brasileiras; (ii) estudar o dimensionamento e estabelecer critérios operacionais de reservatórios e certificação da qualidade da água de reúso; (iii) avaliar a possibilidade e as implicações técnicas e econômicas para a utilização de redes existentes e suas extensões para efetuar a distribuição de água potável de reúso; (iv) desenvolver programas educacionais e de conscientização para promover a aceitação pública da prática de reúso potável direto - argumentos relevantes são associados à garantia do abastecimento e ao fornecimento de água segura aos consumidores de sistemas públicos de abastecimento; e (v) combater o procedimento autoprotecionista e imediatista dos órgãos controladores que deverão ser orientados para desenvolver, normas, padrões e códigos de prática realistas baseados em estudos e pesquisas e não na cópia de normas e diretrizes alienígenas que não representam as condições técnicas, culturais, ambientais e de saúde pública brasileiras.

É inexorável que, dentro de no máximo uma década, a prática do reúso potável direto, utilizando tecnologias modernas de tratamento e sistemas avançados de gestão de riscos e de controle operacional, será, apesar das reações psicológicas e institucionais que a constrangem, a alternativa mais plausível para fornecer água realmente po- 
tável. Além de resolver o problema de qualidade, o reúso potável direto estaria fortemente associado à segurança do abastecimento, pois utilizaria fontes de suprimento disponíveis nos pontos de consumo, eliminando, por exemplo, a necessidade da construção de longas e custosas adutoras, que, geralmente, transferem água para grandes centros urbanos, coletada de áreas afetadas por estresse hídrico.

\section{REFERÊNCIAS}

Arnold, R., (2009), Residuals Organics and Ammonia Nitrogen during SAT of Conventionally Treated Municipal Wastewater, Workshop - Uso e Reúso de Águas Residuárias, Sabesp, São Paulo, SP, 13 de maio;

ATSE-Australian Academy of Technological Sciences and Engineering, (2013), Drinking Water Through Recycling-The Benefits and Costs of Supplying Direct to the Distribution System, p. 128, ISBN 97892138825 5, Melbourne, Australia;

Asano, T., Burton, F.L, Laverenz, H.L., Tsuchihashi, R, Tchobanouglous, G, (2007), Water Reuse - Issues, Technologies, and Applications, Metcalf \& Eddy/AECOM, eds., p. 1.570, Mc Graw Hill, New York;

Baker, R.W., (2006), Membrane Technology and Applications, $2^{\text {nd }}$ Ed., John Wiley \& Sons, Ltd, p. 538, England;

Bowdoin College (2006), Brunswick, ME, USA;

http//www.academic.bowdoin.edu/classics/research/moyer/ html/intro.shtml;

California Department of Public Health - CDPH (2008), Groundwater Recharge Reuse Draft Regulations, California State of California-Health and Human Services Agency, Sacramento, California, USA;

Companhia de Saneamento Básico do Estado de São Paulo, SABESP, (2011), Estudo de Concepção e Projeto Básico do Sistema Produtor São Lourenço -Relatório de Impacto ao Meio Ambiente - RIMA, Encibra S.A.-Estudos e Projetos de Engenharia, Prime Engenharia, Rima, p. 187, março, São Paulo, SP;

Damikouka, I., Katsiri, A., Tzia, C., (2007), Application of HACCP principles in drinking water treatment, Desalination, 210, p.138145

Hashimoto, T., Stedinger, J. R., \& Loucks, D. P. (January 01, 1982). Reliability, resiliency, and 627 vulnerability criteria for water resource system performance evaluation. Water Resources 628 Research, 18, 1.)
Hespanhol, l., (2008), Tratamento avançado de águas para abastecimento publico, apresentado no Seminário sobre Qualidade de Água no Estado de São Paulo, Instituto de Engenharia de São Paulo, 19 de maio, São Paulo, SP;

Hespanhol, I., (2009), O Princípio da Precaução e a Recarga Gerenciada de Aquíferos, ensaio, p.28-29, Revista DAE, $n^{\circ} 179$, ISSN 0101-6040, janeiro, São Paulo;

Hespanhol, I., (2012), "Poluentes Emergentes, Saúde Pública e Reúso Potável Direto”, cap.20, p.501-537, in: Engenharia Ambiental - Conceitos, Tecnologia e Gestão, Coords. Maria do Carmo Calijuri e Davi Gasparian Fernandes Cunha, p. 789, Elsevier Campus. ISBN: 978-85-352-5954-4;

Huang, C. P.,Dong C., Tang. Z., (1993), Advanced chemical oxidation: its present role and potential future in hazardous waste treatment, Waste Management, vol.13, p. 61-77;

Huber, M.M., Canonica, S, Park, G., and von Gunten, U., (2003), Oxidation of pharmaceuticals during ozonation and Advanced oxidation processes, Environmental Science and Technology, vol. 37, no. 5, p.1.016-1.024.

Koch Membrane Systems, (sem data), Industrial Water and Wastewater Treatment, catálogo, p.6, USA;

Leverenz, H.L., Tchobanoglous, G., Asano, T., (2011), Direct Potable Reuse: a future imperative, Journal of Water Reuse and Desalination, IWA Publishing, vol. 1 no. 1, p. 2-10, march, USA;

Mierzwa, J.C. (2009), "Desafios para o tratamento de água de abastecimento e o potencial de aplicação do processo de ultrafiltração", tese apresentada à Escola Politécnica da Universidade de São Paulo para a obtenção do Título de Livre-Docente, pelo Departamento de Engenharia Hidráulica e Ambiental, p.127. São Paulo, SP.

Mierzwa, J.C., Hespanhol, I, (2005), Água na Indústria - Uso Racional e Reúso, Oficina de Textos, p. 143, São Paulo;

Mulder, M. (1996), Basic principles of membrane technology, Kluwer Academic Publishers, $2^{\text {nd }}$ edition, p. 564, United States;

Osmonics Inc.(sem data), The Filtration Spectrum, p.1, USA;

Patti Júnior, E., (2007), Princípio da Precaução - Aspectos Controvertidos e Desafios para a sua Aplicação numa Sociedade de Risco, Mestrado em Direito,p.188, Pontifícia Universidade Católica de São Paulo, Sâo Paulo, SP.

Sabesp-Companhia de Saneamento do Estado de São Paulo, (2011), Estudo de Concepção e Projeto Básico do Sistema Produtor São Lourenço-Relatório do Impacto do Meio Ambiente-RIMA, Encibra S.A., Estudos e Projetos de Engenharia, Prime Engenharia, 187 p., São Paulo; 
Sontheimer, H., (1979), Design criteria and process schemes for GAC filters, J. AAWA, vol. 71, no. 11, p. 618-627;

Swansea University (2006), Wales, UK http//www.swan.ac.uk/classics/staff/ter/grst/What's\%20 what\%20Things/aqueducts/htm;

Tchobanoglous, G, Burton ,(1991), Wastewater Engineering Treatment Disposal and Reuse, 3th edition, Metcalf \& Eddy, p. 1.334, Mc Graw Hill, USA;

Tchobanoglous, G, Burton , F.L., Stensel, H.D., (2003), Wastewater Engineering - Treatment and Reuse, 4th edition, Metcalf \& Eddy, p. 1.819, Mc Graw Hill, USA.

Tchobanoglous, G, Leverenz, H., Nellor, M.H.N., Crook, J., (2011), Direct Potable Reuse - A Path Forward, Water Reuse Research Foundation, p.102, USA;

Vandenbohede, A., Van Houtte, E., Lebbe, L., (2008), Groundwater flow in the vicinity of two artificial recharge recharge ponds in the Belgian coastal dunes. Hydrology Journal, p. 1669-1681, Belgium;

Van der Merwe, B., Du Pisani, P., Menge, J., König, E., (2008), Water Reuse in Windhoek, Namibia: 40 years and still the only case of direct water reuse for human consumption, p.434-454, chapter 24, in: Water Reuse-An International Survey of current practice, issues and needs, Eds. Blanca Jimenez and Takashi Asano, IWA Publishing, London;

Van Houtte, E., Verbauwhede, (2008), Operational experience with indirect potable reuse at the Flemish coast, Desalination, no.218, p.198-207;

World Health Organization-WHO, (2011), Guidelines for Drinking Water Quality, 4 Th ed., p.541, Geneva, Switzerland. 